\title{
Vertebroplasty in the treatment of osteoporotic vertebral compression fractures: patient selection and perspectives
}

This article was published in the following Dove Press journal: Open Access Rheumatology: Research and Reviews

\section{Konstantinos Martikos \\ Tiziana Greggi \\ Francesco Vommaro \\ Luca Boriani \\ Antonio Scarale \\ Paola Zarantonello \\ Giuseppe Carbone \\ Stefano Stallone \\ Riccardo Zucchini}

Spine Deformities Surgery Division, Istituto Ortopedico Rizzoli, Bologna 40I36, Italy
Correspondence: Konstantinos Martikos Spine Deformities Surgery Division, Istituto Ortopedico Rizzoli, I Via Pupilli, Bologna 40136, Italy

Tel +3905I 6366158

Email info@martikos.com

\begin{abstract}
Osteoporotic vertebral fractures represent a constantly increasing pathology that may compromise life quality and general health. Among various treatment options, percutaneous vertebroplasty has been used widely over the past 20 years. Although there is a vast amount of retrospective reports in the literature, high-level evidence has emerged only recently. In this paper, the authors provide a synopsis of the current literature on the efficacy and safety of percutaneous vertebroplasty while also presenting a step-by-step description of the surgical procedure, focusing on details that may help in optimizing quality and safety.
\end{abstract}

Keywords: percutaneous vertebroplasty, vertebral compression fractures, osteoporosis, PMMA

\section{Introduction}

Vertebral compression fractures (VCFs) are the most frequent bone lesions in osteoporotic patients, causing acute or chronic pain and thoracolumbar kyphosis of the spine that in severe cases may compromise respiratory and gastrointestinal function. Complications of VCF may lead to progressive reduction in quality of life, and thus prompt evaluation and effective treatment is required, either conservative or surgical. Conservative treatment (CT) consists in bed rest for several days or weeks, pain treatment with anti-inflammatory or opioid drugs, and thoracolumbar hyperextension brace, followed by physiotherapy. Surgical treatment consists in vertebral augmentation procedures, among which percutaneous vertebroplasty (PV) is traditional and the most widely used, consisting in direct injection of medical cement (polymethylmethacrylate [PMMA]) inside the fractured vertebral body. With $\mathrm{CT}$, pain normally decreases progressively within the first 2-3 weeks, but potential complications related to prolonged immobilization may occur, such as venous thromboembolism or increased risk of mortality. ${ }^{1-3}$ PV offers immediate pain relief, allows for immediate postoperative ambulation, and potential reported risks are related to intraoperatory PMMA leakage into the bloodstream or spinal canal. Various reports have also described increased risk of adjacent vertebral fractures following PV. This paper offers a description of the PV technique, including some useful tips for obtaining satisfying results and minimizing complications, and retraces noteworthy evidence in the literature for optimal patient selection. 


\section{Technique (tips), indications, results, and complications}

Usually, PV is performed with local anesthesia, mainly for two reasons. Patients with adjacentvertebral fractures are frequently aged patients that may present various concomitant pathologies. Avoiding general anesthesia allows for a more subtle surgical impact, preventing potential perioperative respiratory, cardiopulmonary, cognitive, and other complications. The other advantage of local anesthesia is verbal interaction with the patient, which allows verification of direct and constant sensitivity and motor function of lower limbs during the whole surgical procedure and especially during cement injection. In cases of asympyomatic cement leakage inside the spinal canal, the procedure may be halted temporarily or definitively. On the contrary, symptomatic cement leakage inside the spinal canal should be dealt with by open decompression in general anesthesia. Performing PV with local anesthesia is the only way to distinguish in real time between symptomatic and asymptomatic cement leakage.

In aseptic ambient conditions and under fluoroscopic or CT guidance, an 11-13 G bone needle is inserted toward the lateral aspect of the fractured vertebra's pedicle. Pedicle anatomy allows for different safe trajectories for reaching the vertebral body, varying from rather straight trajectories that end up at the lateral aspect of the vertebral body to more converging trajectories capable of reaching the midline of the vertebral body. The authors advise seeking a converging trajectory, in order to achieve symmetric vertebral body augmentation, with a single-side approach per level. Avoiding a double approach per level helps in restricting total operation time, enhances patient compliance related to maintaining a prone position with less possible body movement, and reduces the rate of surgical risks because of fewer surgical maneuvers.

Under image guidance, the needle should thus reach the lateral aspect of the fractured vertebral body and slowly proceed toward the medial aspect of the pedicle. The authors suggest imprinting a cranial or caudal direction at the needle toward the proximal or distal end plate and opposite the fractured end plate, in order to inject PMMA in an unfractured area of the vertebral body. Once the needle reaches the medial aspect of the pedicle, in cases of C-arm fluoroscopy guidance, a lateral image should be obtained. If in lateral view the tip of the needle touches the posterior vertebral wall, the needle is being correctly inserted. If the needle tip is posterior to the vertebral body's posterior wall, then the needle has probably invaded the spinal canal. If the tip of the needle is anterior to the vertebral body's posterior wall, then the needle may be lateral to the vertebral body. If the pedicle trajectory is ideal, we suggest halting needle progression and always performing a biopsy, as preoperative imaging cannot always exclude an underlying malignancy. Performing a biopsy at this point (before progressing through the whole length of the vertebral body with the PV needle) allows obtainment of a substantial amount of tissue with the biopsy needle for microscopic evaluation. Once the biopsy has been performed, the needle may be advanced toward the unfractured end plate, stopping approximatively $1 \mathrm{~cm}$ posteriorly to the anterior wall (a needle tip reaching the anterior-wall cortex in X-rays may be anterior to the vertebral body, due to its rounded shape).

PMMA is generally prepared by mixing a polymer powder with a liquid monomer and waiting until the substance has reached a toothpaste-like consistency. If PMMA is introduced into the vertebral body while still too liquid, there is a high risk of leakage. On the contrary, if PMMA is too solid, it may polymerize inside the injection needle. We thus recommend having everything in place before commencing PMMA preparation. PMMA is then slowly injected by controlled augmentation on both lateral and anteroposterior views. If venous extravasation (anterior or posterior) is detected, injection may be halted for $20-40$ seconds, because PMMA tends to polymerize faster in blood vessels than inside the injection needle. In any case, resumption of augmentation should be done carefully, in order to detect eventual further extravasation. Generally, if any type of leakage or extravasation occurs, the procedure should be halted temporarily or definitely. There is no consensus on the total amount of PMMA that should be introduced inside the vertebral body. At the end of the procedure, in order to avoid PMMA outflowing into posterior soft tissue, pressure inside the injection chamber should be reduced and the needle drawn out slowly.

\section{Evidence in the literature}

The effectiveness of PV for VCF treatment is undoubtedly one of most popular arguments in spine-surgery literature. Despite the vast amount of reported data in orthopedic, neurosurgery, interventional radiology or anesthesiology journals, PV superiority versus CT is still controversial. Various prospective or retrospective studies have reported PV efficacy in pain relief and satisfactory functional 
outcomes, while other studies addressed such complications as neurological or vascular PMMA leakage, as well as adjacent vertebral fractures. ${ }^{4-12}$

In 2009, two randomized trials studying PV as treatment for osteoporotic vertebral fractures ${ }^{13,14}$ were published in the New England Journal of Medicine contesting its efficacy. Neither found any significant difference between vertebroplasty and sham treatment or initiating changes in everyday practice and clinical recommendations, leading various associations to limit indications and recommendations in performing PV. In 2010, AmericanAcademy of Orthopaedic Surgeons guidelines provided a weak recommendation for kyphoplasty and a strong recommendation against $\mathrm{PV} .{ }^{15}$ On the other hand, both studies received a vast amount of criticism regarding design quality and interpretation of results, eg, Kallmes et al described a $42 \%$ crossover rate from sham procedure to PV within 1 month and only $12 \%$ in the opposite direction, thus clearly in favor of PV. Another important factor in interpreting these two famous studies is the fact that they included fractures as old as 1 year, contradicting PV's main benefit, which is immediate pain improvement and early functional recovery after acute VCF. In fact, the reduced efficacy of PV in fractures older than 1 year in terms of pain relief and functional disability had already been stated in previous studies. ${ }^{16}$ Nevertheless, despite the controversies, at that time these two studies represented the highest level of evidence regarding treatment of osteoporotic fractures with PMMA injection.

After the New England Journal of Medicine studies, a series of papers with high-level evidence emerged in favor of PMMA treatment. In 2012, a meta-analysis of 27 level I and II studies by Papanastasiou et al on PV, kyphoplasty, and $\mathrm{CT}$ for VCF treatment concluded that PMMA procedures offered better pain relief and fewer additional VCFs than $\mathrm{CT} .{ }^{17}$ The randomized but not blinded Vertos II study of over 200 patients with VCF, comparing CT to PV (no sham procedure), concluded that $\mathrm{PV}$ was superior in pain relief at both 1 month and 1 year. $^{18}$

In 2016, two blinded randomized controlled trials demonstrated statistically significant benefits in pain improvement and functional outcome with PV when compared with sham treatments. Clark et al compared PV to a sham procedure in patients with acute VCFs, and concluded that PV reduced pain to a significant degree, improved disability, and achieved greater vertebral height restoration. ${ }^{19}$ The other randomized controlled trial, by Hansen et al, concluded that there was a statistically significant VAS-score reduction in PV patients in comparison to sham-procedure patients. ${ }^{20}$

Rousing et al conducted an open-label, randomized study (fracture age $<8$ weeks) comparing PV with CT for acute VCFs, reporting immediate and significant pain relief following PV, both immediately and at 1 month. However, no di $\square$ erence in pain scores was found between groups at 3 and 12 months, suggesting that the role of PV may be as a short-term invasive method of pain control in those who fail CT or for those in whom $\mathrm{CT}$ and the accompanying immobilization carry serious risks. ${ }^{21}$ Similar results were found in another recent retrospective report comparing $\mathrm{PV}$ to $\mathrm{CT}$, finding no statistically significant differences between the two treatments at a mean 2year follow up. ${ }^{10}$

The most frequent complication of PV is PMMA leakage, asymptomatic in the vast majority of cases. In a small number of cases, there may be radiculopathy due to PMMA leakage in the neural foramen that in most cases is transitory and rarely requires open decompression. Venous PMMA embolization is rare, although there have been reports of pulmonary embolism. $^{22,23}$ Potential negative mechanical effects of cemented vertebrae upon adjacent osteoporotic levels has been described by previous studies, ${ }^{9-12}$ with reports of new VCF incidence being extremely variable (8\%-52\%). Nevertheless the debate on whether PV causes an increased risk of adjacent VCFs is still open.

\section{Conclusion}

It is not possible to draw definite conclusions regarding PV's efficacy over CV for VCF treatment. There is a considerable amount of literature in favor of PV treatment, especially regarding immediate pain reduction and early functional recovery, in contrast to standard $\mathrm{CT}$, which requires prolonged bed rest, drug therapy, bracing, and physical therapy. Although PV provides pain relief in the acute/subacute period, long-term outcomes seem to be similar to those obtained with CT. In conclusion, PV remains a valid treatment option in treating VCFs, and is efficient in prompt pain reduction in acute/subacute fractures. PV is a secure treatment, although complications may occur. In order to reduce complication rates, the aforementioned patient-selection criteria must be respected. PV is mainly indicated in type A1 fractures with vertebral body-height reduction not superior to two thirds of normal height. All other types of fractures should be considered at high risk of PMMA leakage. PV should be absolutely avoided in fractures with posterior-wall involvement, because of elevated risk of spinal cord damage. The best 
indication based on the literature is represented by acute osteoporotic fractures in patients that require early ambulation, thus avoiding potential complications resulting from prolonged bed rest and prolonged NSAID or opioid assumption. Elderly patients that require early posttraumatic ambulation or even younger patients that refuse bracing or bed rest may represent possible candidates for PV. The main arguments regarding PV that still need to be addressed with controlled trials are long-term functional outcomes and long-term effect on adjacent spinal levels.

\section{Disclosure}

The authors report no conflicts of interest in this work.

\section{References}

1. Silverman SL. The clinical consequences of vertebral compression fracture. Bone. 1992;13(2):S27-S31.

2. Lyritis GP, Mayasis B, Tsakalakos N, et al. The natural history of the osteoporotic vertebral fracture. Clin Rheumatol. 1989;8(supplement 2):66-69. doi:10.1007/BF02207237

3. Bliuc D, Nguyen ND, Milch VE, Nguyen TV, Eisman JA, Center JR. Mortality risk associated with low-trauma osteoporotic fracture and subsequent fracture in men and women. J Am Med Assoc. 2009;301 (5):513-521. doi:10.1001/jama.2009.50

4. Lamy O, Uebelhart B, Aubry-Rozier B. Risks and benefits of percutaneous vertebroplasty or kyphoplasty in the management of osteoporotic vertebral fractures. Osteoporos Int. 2014;25:807-819. doi:10.1007/s00198-013-2574-4

5. Lee BJ, Lee SR, Yoo TY. Paraplegia as a complication of percutaneous vertebroplasty with polymethylmethacrylate: a case report. Spine (Phila Pa). 1976;2002(27):E419-22.

6. Alfonso Olmos M, Silva Gonzalez A, Duart Clemente J, et al. Infected vertebroplasty due to uncommon bacteria solved surgically: a rare and threatening life complication of a common procedure: report of a case and a review of the literature. Spine (Phila Pa 1976). 2006;31:E770-3. doi:10.1097/01.brs.0000240202.91336.99

7. Edidin AA, Ong KL, Lau E, Kurtz SM. Morbidity and mortality after vertebral fractures: comparison of vertebral augmentation and nonoperative management in the medicare population. Spine (Phila Pa 1976). 2015;40(15):1228-1241. doi:10.1097/BRS.0000000000000992

8. Yeom JS, Kim WJ, Choy WS, Lee CK, Chang BS, Kang JW. Leakage of cement in percutaneous transpedicular vertebroplasty for painful osteoporotic compression fractures. J Bone Joint Surg Br. 2003;85:8389.

9. Borensztein M, Willhuber GOC, Martinez MLP, Gruenberg M, Sola CA, Velan O. Analysis of risk factors for new vertebral fracture after percutaneous vertebroplasty. Global Spine J. 2018;8(5):446-452. doi: $10.1177 / 2192568217732988$
10. Martikos K, Greggi T, Faldini C, Vommaro F, Scarale A. Osteoporotic thoracolumbar compression fractures: long term retrospective comparison between vertebroplasty and conservative treatment. Eur Spine J. 2018;27:244-247. doi:10.1007/s00586-0185605-1

11. Lin EP, Ekholm S, Hiwatashi A, Westesson PL. Vertebroplasty: cement leakage into the disc increases the risk of new fracture of adjacent vertebral body. AJNR Am J Neuroradiol. 2004;25:175-180.

12. Voormolen MH, Lohle PN, Juttmann JR, van der Graaf Y, Fransen H, Lampmann LE. The risk of new osteoporotic vertebral. compression fractures in the year after percutaneous vertebroplasty. J Vasc Interv Radiol. 2006;17:71-76. doi:10.1097/01.RVI.0000190910.43602.3C

13. Buchbinder R, Osborne RH, Ebeling PR, et al. A randomized trial of vertebroplasty for painful osteoporotic vertebral fractures. $N$ Engl J Med. 2009; 361(6):557-568. Global Spine Journal 2018, Vol. 8(5) 446-452. doi:10.1056/NEJMoa0900429

14. Kallmes DF, Comstock BA, Heagerty PJ, et al. A randomized trial of vertebroplasty for osteoporotic spinal fractures. $N$ Engl J Med. 2009;361(6):569-579. doi:10.1056/NEJMoa0900563

15. Esses SI, McGuire R, Jenkins J, et al. American academy of orthopaedic surgeons clinical practice guideline on: the treatement of osteoporotic spinal compression fractures. J Bone Joint Surg Am. 2011;93(20):1934-1936. doi:10.2106/JBJS.J.00711

16. Kallmes DF, Jensen ME. Percutaneous vertebroplasty. Radiology. 2003;229(1):27-36. doi:10.1148/radiol.2291020222

17. Papanastassiou ID, Phillips FM, Van Meirhaeghe J, et al. Comparing effects of kyphoplasty, vertebroplasty, and nonsurgical management in a systematic review of randomized and non-randomized controlled studies. Eur Spine J. 2012;21(9):1826-1843. doi:10.1007/s00586012-2314-z

18. Klazen C, Lohle P, de Vries J, et al. Vertebroplasty versus conservative treatment in acute osteoporotic vertebral compression fractures (VERTOS II): an open-label randomised trial. Lancet. 2010;376:1085-1092. doi:10.1016/S0140-6736(10)60954-3

19. Clark W, Bird P, Gonski P, et al. Safety and efficacy of vertebroplasty for acute painful osteoporotic fractures (VAPOUR): a multicentre, randomised, double-blind, placebo-controlled trial. Lancet. 2016;388 (10052):1408-1416. doi:10.1016/S0140-6736(16)31341-1

20. Hansen EJ, Simony A, Rousing R, LY C, Tropp H, Andersen MO. Double blind placebo-controlled trial of percutaneous vertebroplasty (VOPE). Global Spine J. 2016;6(suppl 1):GO106. doi:10.1055/s0036-1582763

21. Rousing R, Hansen KL, Andersen MO, Jespersen SM, Thomsen K, Lauritsen JM. Twelve-months follow up in forty-nine patients with acute/semiacute osteoporotic vertebral fractures treated conservatively or with percutaneous vertebroplasty: a clinical randomized study. Spine. 2010;35(5):478-482. doi:10.1097/BRS.0b013e3181b $71 \mathrm{bd} 1$

22. Choe DH, Marom EM, Ahrar K, Truong MT, Madewell JE. Pulmonary embolism of polymethyl methacrylate during percutaneous vertebroplasty and kyphoplasty. Am J Roentgenol. 2004;183 (4):1097-1102. doi:10.2214/ajr.183.2.1830535

23. Padovani B, Kasriel O, Brunner P, Peretti-Viton P. Pulmonary embolism caused by acrylic cement: a rare complication of percutaneous vertebroplasty. Am J Neuroradiol. 1999;20(3):375-377. 


\section{Publish your work in this journal}

Open Access Rheumatology Research and Reviews is an international, peer-reviewed, open access journal publishing original research, reports, editorials, reviews and commentaries on all aspects of clinical and experimental rheumatology in the clinic and laboratory including the following topics: Pathology, pathophysiology of rheumatological diseases; Investigation, treatment and managemen of rheumatological diseases; Clinical trials and novel pharmacological approaches for the treatment of rheumatological disorders. The manuscript management system is completely online and includes a very quick and fair peer-review system, which is all easy to use. Visit http://www.dovepress.com/testimonials.php to read real quotes from published authors. 